\title{
Migration of metallic mercury in the hand
}

\author{
Neil J Wells BSc MD, James C Boyle MD FRCSC, Victor Wood MD FRCPC \\ Division of Plastic Surgery and Burns, University of British Columbia, Vancouver, \\ British Columbia
}

\begin{abstract}
NJ Wells, JC Boyle, V Wood. Migration of metallic mercury in the hand. Can J Plast Surg 1996;4(2):114-116. A case of an unusual injury to the hand involving a broken thermometer, resulting in migration of mercury within the tissues requiring surgical removal, is described.
\end{abstract}

\section{Migration de mercure métal dans la main}

RÉSUMÉ : Un cas de blessure inhabituelle à la main impliquant un thermomètre brisé, et qui a entraîné une migration du mercure à l'intérieur des tissus exigeant une extraction chirurgicale, est décrit.

Subcutaneous injection of metallic mercury is uncommon and most articles have emphasized the potential systemic complications $(1,2)$. Only a few articles have dealt with the local injury describing it as a foreign body granuloma-type reaction $(3,4)$. This paper reports a case of palmer injection of mercury from a broken thermometer and the unusual local response.

\section{CASE REPORT}

A 34-year-old right hand dominant female suffered a puncture wound to the left hand over the base of the thenar eminence. At the time of initial assessment her hand examination was normal except for a small puncture wound at the base of the thenar eminence. At that time, the wound was opened over $1 \mathrm{~cm}$ and the visible superficial mercury was removed. There was felt to be residual mercury at a deeper level so a radiograph was obtained which confirmed this (Figure 1).

The patient was referred to a hand surgeon and examined 12 days after the initial injury. The clinical examination was essentially unchanged; however, a repeat radiograph was obtained. This demonstrated the presence of the mercury but it appeared to have spread more proximally and distally compared with the initial radiograph (Figure 2).

The patient underwent surgical removal of the mercury with the aid of fluoroscopy and loupe magnification. Intraoperatively it was noted that the mercury started in close proximity to the superficial palmar arch and extended along the fascia of the first lumbrical. The fascia and mercury were excised en bloc to remove all of the mercury droplets. A follow-up radiograph showed no remaining mercury and the patient has healed without incident. 


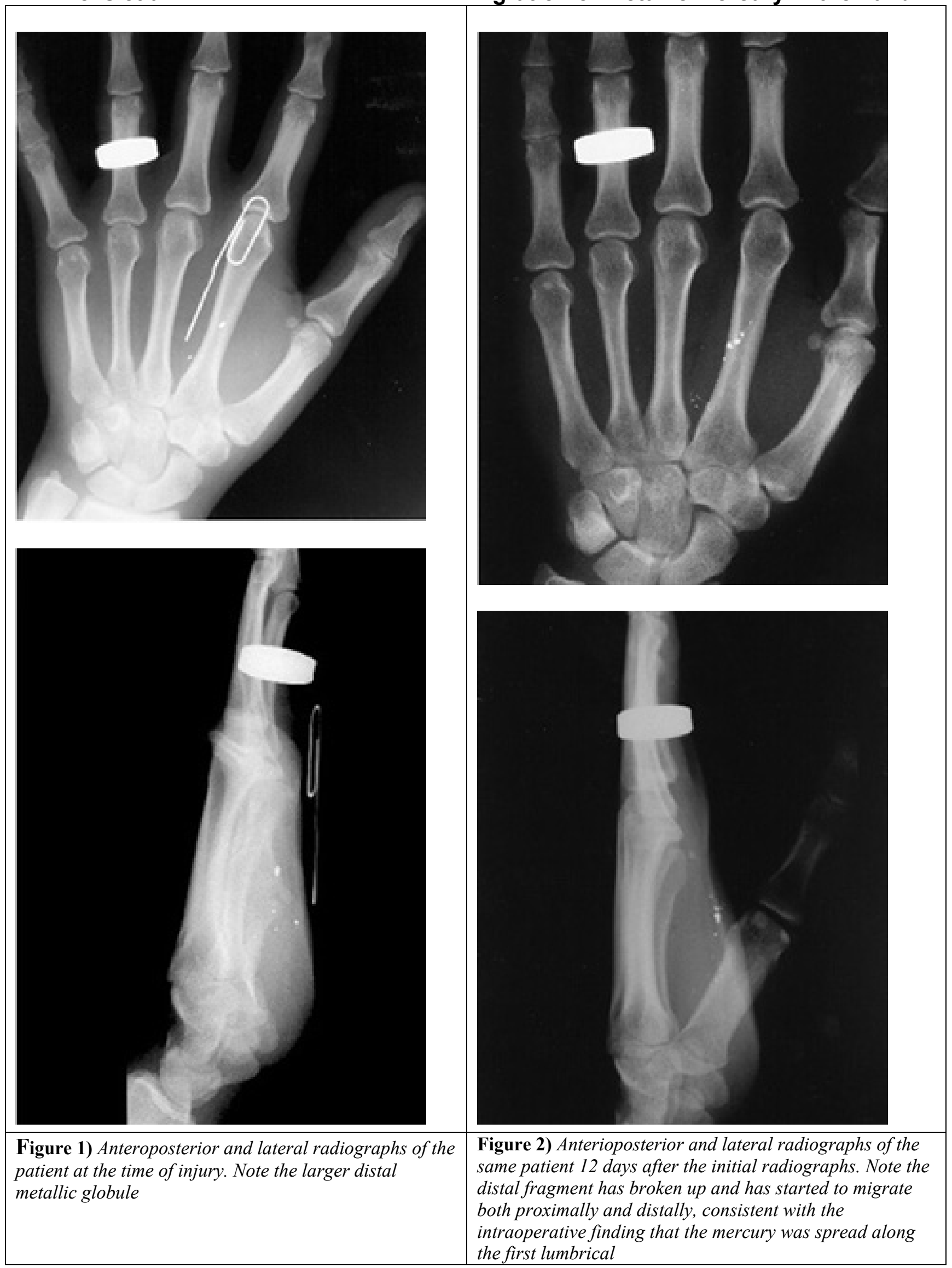


Migration of metallic mercury in the hand

\section{DISCUSSION}

The effects of mercury depend on its form and route of absorption. Organic mercury and mercurial salts are not a problem with injection but produce significant effects via oral absorption whereas metallic mercury is poorly absorbed orally, and causes a problem via the cutaneous route. Injury and toxicity as a result of accidental or intentional injection of metallic mercury are uncommon. The effects are caused by the wide distribution throughout all organ systems of the oxidized forms of mercury, and have ranged from a local inflammatory reaction $(2,4)$ to systemic effects on the kidneys, lung and central nervous system $(5,6)$. The history may be unclear in some cases and symptoms may range from local edema to nausea, vomiting, gastrointestinal bleeding, renal failure and neurologic complaints.

The unpredictability of the bodily response and the possibility of these systemic effects led to the early surgical excision in this case. Only at the time of excision, with the observation that the mercury was lying along the fascia of the first lumbrical, was it appreciated that the mercury had migrated along this fascial plane. This migration of the mercury has not been documented before and raises concern regarding the potential spread of the mercury through the fascial planes and sheaths of the hand with the subsequent possibility of diffuse fibrosis.

With the pre-existing knowledge of the systemic risks and now the possibility of a more diffuse local reaction we recommend early complete surgical removal which can be accomplished with the aid of fluoroscopy and loupe magnification.

\section{REFERENCES}

1. Krohn IT, Solof A, Mobini J, Wagner DK. Subcutaneous injection of metallic mercury. JAMA 1980;243:548-9.

2. Rachman R. Soft tissue injury by mercury from a thermometer: A case report and review of the literature. Am J Clin Pathol 1974;61:296-300.

3. Baruch AD, Haas A. Injury to the hand with metallic mercury. J Hand Surg 1984;9A:446-8.

4. Cole JK, Holbrook JL. Focal mercury toxicity: a case report. J Hand Surg 1994;19A:602-3.

5. Johnson HRM, Koumides O. Unusual case of mercury poisoning.

BMJ 1967;i:340-1.

6. Popper L. Death following injury by a thermometer. Wien Med Wochenschr 1966;116:779-80. 